\title{
The analytics of the wage effect of immigration
}

\author{
George J Borjas ${ }^{1,2,3}$
}

Correspondence: gborjas@harvard.edu ${ }^{1}$ Harvard University, Cambridge, MA 02138, USA

${ }^{2}$ NBER, Cambridge, MA 02138, USA Full list of author information is

available at the end of the article

\begin{abstract}
The theory of factor demand has important implications for the study of the impact of immigration on wages. This paper derives the theoretical implications in the context of a general equilibrium model where the wage impact depends on the elasticity of product demand, the rate at which the consumer base expands as immigrants enter the receiving country, the elasticity of supply of capital, and the elasticity of substitution among inputs of production. The constraints imposed by the theory can be used to check the plausibility of the many contradictory claims that appear throughout the immigration literature.
\end{abstract}

JEL codes: J23; J61; F22

Keywords: Immigration; Wage impact of immigration; Factor demand theory

\section{Introduction}

The resurgence of large-scale immigration motivated the development of a large literature that examines how labor markets in both receiving and sending countries react to the immigration-induced change in supply. The textbook model of a competitive labor market suggests that higher levels of immigration should lower the wage of competing workers and increase the wage of complementary workers, at least in the short run. Despite the common-sense intuition behind these predictions, the empirical literature seems full of contradictory results. Some studies claim that immigration has a substantial impact on wages in receiving and sending countries (e.g., Borjas 2003; Mishra 2007), while other studies claim the impact is negligible (Card 2005; Ottaviano and Peri 2012).

This paper takes a step back from the empirical debate and asks a simple question: What does factor demand theory have to say about the potential wage impact of immigration-induced supply shifts? Since Marshall's time, economists have had a good understanding of the variables that generate elastic or inelastic labor demand curves, and how the elasticity of labor demand is affected by substitution and scale effects ${ }^{1}$. Unfortunately, much of the empirical literature on the wage impact of immigration (particularly in the 1990s) disregarded practically all of these insights, and instead took a data-mining approach: running regressions or estimating difference-in-differences models to examine if the wage evolution in labor markets most affected by immigration differed from that observed in other markets. Few of these studies were guided or informed by the implications of factor demand theory.

More recently, beginning with Card (2001) and Borjas (2003), the literature has taken a turn and begun to pay closer attention to the underlying economics of the problem $^{2}$. This paper derives the implications of factor demand theory for the study of

(C) 2013 Borjas; licensee Springer. This is an open access article distributed under the terms of the Creative Commons Attribution License (http://creativecommons.org/licenses/by/2.0), which permits unrestricted use, distribution, and reproduction in any medium, provided the original work is properly cited. 
the wage impact of immigration in competitive labor markets. Specifically, it examines the question in the context of a general equilibrium model that explicitly introduces such factors as the elasticity of product demand, the rate at which the consumer base expands as immigrants enter the country, the elasticity of supply of capital, and the elasticity of substitution across inputs of production.

The analysis makes two contributions. First, the model generates a closed-form solution of the wage effect of immigration, allowing us to easily generate back-of-the-envelope estimates under a large number of potential scenarios. Not surprisingly, factor demand theory imposes severe constraints on the potential sign and numerical value of these presumed wage effects. These constraints can be used to check the plausibility of the many contradictory claims that appear throughout the empirical immigration literature.

Second, the model demonstrates that the impact of immigration on the wage level in the receiving country depends on completely different parameters than its impact on the wage distribution-as long as the analysis builds in technical restrictions that are widely used in the empirical literature. The "separability" of these results again allows simple back-of-the-envelope calculations that suggest the possible range of estimates for the distributional impact of immigration.

It is important to emphasize at the outset that by deriving the wage impact of immigration in the context of a competitive labor market, the analysis may be overlooking potentially interesting implications introduced by the possibility that some (many?) immigrants are employed by firms with market power. Unfortunately, the implications of immigration-induced supply shifts in the context of imperfectly competitive labor markets have not yet been fully developed.

Similarly, the analysis uses the "standard" assumption of constant returns to scale to derive the implications of supply shocks for the wage structure. It is obvious that the implications could be quite different when there are either economies or diseconomies of scale. The growing literature that examines the impact of high-skill immigration (Waldinger 2010; Borjas and Doran 2012) attempts to determine if high-skill immigrants impart sufficiently strong human capital externalities on the pre-existing workforce to generate increasing returns. In contrast, there has been remarkably little interest (Rasmussen 2013) in examining the impact of immigration in the presence of fixed factors that lead to decreasing returns.

\section{Preliminaries: homogeneous labor in a one-good closed economy}

It is instructive to begin with the simplest model of a competitive labor market: a single aggregate good, $Q$, is produced using a production function that combines capital $(K)$ and a homogeneous labor input $(L)$. The aggregate production function, $Q=f(K, L)$, is assumed to be linear homogeneous. The relevant derivatives of the production function exist, with $f_{K}$ and $f_{L}>0$, and $f_{K K}$ and $f_{L L}<0$. Linear homogeneity implies that $f_{K L}>0$.

The elasticity of complementarity for any input pair $i$ and $j$ is $c_{i j}=f_{i j} f / f_{i} f_{j}^{3}$. Linear homogeneity implies that a weighted average of these elasticities equals zero:

$$
\sum_{j} s_{j} c_{i j}=0
$$

where $s_{j}$ is the income share accruing to input $j$. 
The product price is fixed at $p$. In a competitive market, each input price is equal to its value of marginal product:

$$
\begin{aligned}
& r=p f_{K}, \\
& w=p f_{L},
\end{aligned}
$$

where $r$ is the price of capital and $w$ is the wage rate.

Consider two polar situations: the short run and the long run. By definition, the capital stock is fixed in the short run and the price of capital is fixed in the long run. Suppose an immigrant influx increases the size of the workforce. By differentiating Equations (2a) and (2b), it is easy to show that in the short run: ${ }^{4}$

$$
\begin{aligned}
& \left.\frac{d \log r}{d \log L}\right|_{d K=0}=s_{L} c_{K L}>0 . \\
& \left.\frac{d \log w}{d \log L}\right|_{d K=0}=s_{L} c_{L L}<0,
\end{aligned}
$$

The derivative $d \log w / d \log L$ will be called the "wage elasticity" of immigration. The short-run wage elasticity must be negative because $c_{L L}<0$. As noted above, linear homogeneity implies that capital and labor are complements, hence $c_{K L}>0$. This complementarity ensures that capital becomes more valuable as the immigration-induced supply shock increases the size of the workforce. Immigration has a short-run distributional impact: wealth is shifted away from workers and towards those who own the productive resources in the immigrant-receiving country.

The distributional impact, however, disappears in the long run. Differentiating the marginal productivity condition in Equation (2a) implies that the immigration-induced change in the capital stock is:

$$
\left.\frac{d \log K}{d \log L}\right|_{d r=0}=-\frac{s_{L} c_{K L}}{s_{K} c_{K K}}=1
$$

where the last equality follows from Equation (1). Linear homogeneity implies that the capital stock and the size of the workforce will both grow (in percentage terms) by exactly the same amount. The long-run wage elasticity is then given by:

$$
\left.\frac{d \log w}{d \log L}\right|_{d r=0}=s_{K} c_{K L}+s_{L} c_{L L}=0,
$$

where the last equality also follows from (1). In the long run, the receiving country's wage is independent of immigration. The intuition is clear: The linear homogeneity of the production function implies that input prices depend only on the capital/labor ratio. The assumption that the price of capital is constant implies that the capital/labor ratio is also constant. If immigrants increase the size of the workforce by 10 percent, the capital stock must eventually also increase by 10 percent. In the end, the wage must return to its pre-immigration equilibrium.

It is possible to obtain some insights into the potential magnitude of the short-run wage elasticity by specifying a functional form for the production function. Suppose, in 
particular, that the aggregate production function is CES, so that $Q=\left[\alpha K^{\delta}+(1-\alpha) L^{\delta}\right]^{1 / \delta}$, where $0<\alpha<1$, and $\delta \leq 1$. The elasticity of substitution between labor and capital is defined as $\sigma=1 /(1-\delta)$. The short-run wage elasticity is then given by: ${ }^{5}$

$$
\left.\frac{d \log w}{d \log L}\right|_{d K=0}=-(1-\delta) s_{K} .
$$

The theory has very specific implications about the numerical value of the short-run wage effect if the production function were Cobb-Douglas (so that $\delta=0$, or equivalently $\sigma=1$ ). Labor's share of income in the United States has hovered around 0.7 for some decades. Equation (7) then implies that the short-run wage elasticity is -0.3 . One would then expect the wage elasticity to lie between 0.0 and -0.3 , depending on the extent to which capital has adjusted to the presence of the immigrant influx.

\section{A two-good economy with homogeneous labor}

I now expand the basic model in several ways. First, I assume that there are two goods in the economy; one good is produced domestically and the other good is imported ${ }^{6}$. Second, I allow for changes in product demand both because immigration may have changed the price of the domestically produced product (encouraging consumers to change their quantity demanded) and because immigrants themselves will consume the product. Finally, I explicitly introduce a supply curve of domestic capital. The resulting general equilibrium model has much in common with derivations of Marshall's rules of derived demand. The technical details are summarized in the Mathematical Appendix.

Two goods are consumed in a large economy: good $q$ is produced domestically and good $y$ is imported ${ }^{7}$. To fix ideas, I initially assume that the price of the imported good $y$ is set in the global marketplace (or, alternatively, that it is produced at constant marginal cost). In this context, the price of $y$ is the numeraire and set to unity. I will relax this assumption below and introduce an upward-sloping foreign export supply curve for $y$.

Each consumer $j$ has the quasilinear utility function:

$$
U(y, q)=y+g_{j}^{*} \frac{q^{\xi}-1}{\xi},
$$

where the weight $g$ "reflects the consumer's relative preference for the domestic good and may be different for different consumers. I assume that the utility function is quasiconcave, so that $\xi<1$. Let $Z$ be the consumer's income. The budget constraint is given by:

$$
Z=y+p q
$$

Utility maximization implies that the product demand function for the domestic good is:

$$
q_{j}=g_{j} p^{-1 /(1-\xi)}
$$

where $q_{j}$ is the amount of the good consumed by consumer $j$; and $g_{j}$ is the rescaled person-specific weight. The quasilinear functional form for the utility function implies that the consumer's demand for the domestic product does not depend on his income. The assumption that there are no wealth effects will also be relaxed below. 
Three types of persons consume good $q$ : domestic workers, domestic capitalists, and consumers in other countries. Let $C_{L}$ be the number of domestic workers, $C_{K}$ be the number of domestic capitalists, and $C_{X}$ be the number of consumers in the "rest of the world" ${ }^{\prime}$. I assume that all consumers have the same quasilinear utility function in (8), but that the weighting factor $g$ may differ among the various types of consumers. The total quantity demanded by domestic consumers $\left(Q_{D}\right)$ and foreign consumers $\left(Q_{X}\right)$ is then given by:

$$
\begin{aligned}
& Q_{D}=\left(g_{L} C_{L}+g_{K} C_{K}\right) p^{-1 /(1-\xi)}, \\
& Q_{X}=g_{X} C_{X} p^{-1 /(1-\xi)} .
\end{aligned}
$$

Balanced trade requires that expenditures on the imported good $y$ equal the value of the exports of good $q$ :

$$
w L+r K-\left(g_{L} C_{L}+g_{K} C_{K}\right) p^{-\xi /(1-\xi)}=g_{X} C_{X} p^{-\xi /(1-\xi)},
$$

where $(w L+r K)$ gives the total payment to domestic factors of production $L$ and $K$. In a competitive market, the payment to each factor of production equals its value of marginal product. If the production function is linear homogeneous, Euler's theorem implies that the expression in (12) can be rewritten as:

$$
w L+r K=p\left(f_{L} L+f_{K} K\right)=p Q=\left[g_{L} C_{L}+g_{K} C_{K}+g_{X} C_{X}\right] p^{-\xi /(1-\xi)} .
$$

where $f_{i}$ is the marginal product of factor $i$. It follows that aggregate market demand for the domestic good is given by:

$$
Q=C p^{-1 /(1-\xi)},
$$

where $C=g_{L} C_{L}+g_{K} C_{K}+g_{x} C_{X}$, the (weighted) number of consumers.

An important question arises: How does an immigration-induced increase in the size of the workforce affect the size of the consumer base for the domestic product? ${ }^{9}$ Let $C(L)$ be the function that relates the number of consumers to the number of workers, and let $\phi=d \log C / d \log L$. An important special case occurs when the elasticity $\phi=1$, so that the immigrant influx leads to a proportionately equal increase in the (weighted) number of consumers and the number of workers. I will refer to the assumption that $\phi=1$ as the case of product market neutrality. The "neutrality," of course, refers to the fact that the immigration-induced supply shift leads to the same relative increase in the size of the consumer base and in the size of the workforce.

It is easy to allow for different product demand preferences between immigrants and natives by allowing for non-neutrality, i.e., by allowing for deviations from unity in the elasticity $\phi$. For example, if immigrants prefer consuming the imported good, an immigrant influx that increases the size of the workforce by $x$ percent may lead to a smaller percent increase in the number of "effective" consumers for the domestic good.

Equation (14) shows that an immigration-induced supply shift will have two distinct effects in the domestic labor market through product demand: First, the price of the domestic good might change, moving current consumers along the existing product demand curve; second, because immigrants are themselves "new" consumers, the market product demand curve will shift out and the magnitude of this shift will depend on $\phi^{10}$. 
It is analytically convenient to solve the model by using the inverse product demand function:

$$
p=C^{\eta} Q^{-\eta},
$$

where $\eta$ is the inverse price elasticity of demand, with $\eta=1-\xi>0$, where the strict inequality follows from the assumed quasiconcavity of the utility function in (8).

The production technology for the domestic product is given by the CES production function:

$$
Q=\left[\alpha K^{\delta}+(1-\alpha) L^{\delta}\right]^{1 / \delta},
$$

where the elasticity of substitution between labor and capital is $\sigma=1 /(1-\delta)$.

Finally, the supply of domestic capital is given by the inverse supply function:

$$
r=K^{\lambda}
$$

where $\lambda \geq 0$, and is the inverse elasticity of supply of capital. The two special cases introduced in the previous section for the short run and the long run correspond to $\lambda=\infty$ and $\lambda=0$, respectively.

In a competitive market, input prices equal the value of marginal product:

$$
\begin{aligned}
& r=\alpha C^{\eta} Q^{1-\delta-\eta} K^{\delta-1} . \\
& w=(1-\alpha) C^{\eta} Q^{1-\delta-\eta} L^{\delta-1} .
\end{aligned}
$$

Let $d \log L$ represent the immigration-induced percent change in the size of the workforce. By differentiating Equations (18a) and (18b), and allowing for the fact that the supply of capital is given by Equation (17), it can be shown that: ${ }^{11}$

$$
\frac{d \log w}{d \log L}=\frac{-\lambda(1-\delta-\eta) s_{K}}{(1+\lambda-\delta)-(1-\delta-\eta) s_{K}}-\frac{(1+\lambda-\delta) \eta(1-\phi)}{(1+\lambda-\delta)-(1-\delta-\eta) s_{K}} .
$$

Consider initially the special case of product market neutrality (i.e., $\phi=1$ ), so that immigration expands the size of the consumer pool by the same proportion as its expansion of the workforce. The wage elasticity then reduces to:

$$
\left.\frac{d \log w}{d \log L}\right|_{\phi=1}=\frac{-\lambda(1-\delta-\eta) s_{K}}{(1+\lambda-\delta)-(1-\delta-\eta) s_{K}} .
$$

In the long run, $\lambda=0$ and the wage elasticity goes to zero. Note also that the denominator of Equation (19a) is unambiguously positive ${ }^{12}$. As long as there is incomplete capital adjustment $(\lambda>0)$, therefore, the wage elasticity will be negative if $(1-\delta-\eta)>0$. Define $\eta$ " to be the elasticity of product demand (i.e., $\eta^{\prime \prime}=1 / \eta$ ). It is then easy to show that $(1-\delta-\eta)>0$ implies that:

$$
\eta^{*}>\sigma \text {. }
$$

In other words, even after allowing for a full response by all consumers in the product market, the wage effect of immigration will be negative if there is incomplete capital adjustment and if it is easier for consumers to substitute among the available goods than it is for producers to substitute between labor and capital. This latter condition, of course, has a familiar ring in labor economics-as it happens to be identical to the 
condition that validates Marshall's second rule of derived demand: An increase in labor's share of income leads to more elastic demand "only when the consumer can substitute more easily than the entrepreneur" (Hicks, 1932, p. 246).

It turns out, however, that the condition in Equation (20) arises independently in a political economy model of immigration. In particular, the restriction that $\eta^{\prime \prime}>\sigma$ is a second-order condition to the problem faced by a social planner trying to determine the optimal amount of immigration in the context of the current model. One important feature of the competitive market model presented in this section is that the wagesetting rule ignores the fact that an additional immigrant affects product demand, so that the marginal revenue product of an immigrant is not equal to his value of marginal product. Suppose a social planner internalizes this externality and wishes to admit the immigrant influx that maximizes gross domestic product net of any costs imposed by immigration ${ }^{13}$. More precisely, the social planner wishes to maximize:

$$
\Omega=p Q-F h=C^{\eta} Q^{1-\eta}-F h,
$$

where $F$ gives the number of immigrants and $h$ gives the (constant) cost of admitting an additional immigrant (perhaps in terms of providing social services, etc.). For simplicity, consider the case with product market neutrality. In the Mathematical Appendix, I show that the second-order conditions for this maximization problem are satisfied if: ${ }^{14}$

$$
(1-\eta)>0, \text { and }(1-\delta-\eta)>0 .
$$

In short, as long as the size of the immigrant influx is optimal, the wage elasticity in Equation (19a) must be negative. In that case, the scale effect resulting from immigration-regardless of whether it occurs through an expansion of the capital stock or through an expansion in product demand-can never be sufficiently strong to lead to a wage increase.

It is easy to measure the size of the scale effect triggered by immigration by considering the simple case of a Cobb-Douglas economy in the short run. The wage elasticity in (19a) then collapses to:

$$
\left.\frac{d \log w}{d \log L}\right|_{\substack{\phi=1 \\ \delta=0 \\ \lambda=\infty}}=-(1-\eta) s_{K} .
$$

By contrasting this elasticity with the analogous effect in the one-good model presented in Equation (7), it is easy to see that the scale effect of immigration equals $\eta s_{K}$. In the absence of the scale effect, the wage elasticity would equal -0.3 . If the inverse elasticity of product demand is 0.5 (implying a product demand elasticity of 2.0 ), the wage elasticity would fall to -0.15 . In other words, the short-run adverse effect of immigration on the wage can be greatly alleviated through increased product demand-as long as the product demand elasticity is sizable.

It is important to emphasize that the wage effect will not disappear in the long run if the product market neutrality assumption does not hold. Consider, for example, the case where immigration does not expand the size of the consumer base as rapidly as it expands the size of the workforce (i.e., $\phi<1$ ). The second term in (19) is then negative 
and does not vanish as $\lambda$ goes to zero. In other words, there is a permanent wage reduction because there are "too many" workers and "too few" consumers. This result has interesting implications for the study of immigration when immigrants send a large fraction of their earnings to the sending country in the form of remittances. The negative effect of remittances on wages in the receiving country is permanent; it does not disappear even after capital has fully adjusted to the immigrant influx. Note, however, that it is also possible for immigration to generate permanent wage gains if $\phi>1$ and the immigrants are "conspicuous consumers" of the domestic product ${ }^{15}$.

The wage consequences of even slight deviations from product market neutrality can be sizable. As an illustration, consider the long run effect in a Cobb-Douglas economy. The first term in Equation (19) vanishes and the wage elasticity reduces to:

$$
\left.\frac{d \log w}{d \log L}\right|_{\substack{\delta=0 \\ \lambda=0}}=\frac{-\eta(1-\phi)}{1-(1-\eta) s_{K}} .
$$

Suppose that $\phi=0.8$, so that an immigration-induced doubling of the workforce increases the size of the consumer pool by 80 percent. Suppose again that the inverse elasticity of product demand $\eta$ is 0.5 . Equation (24) then predicts that the long-run wage elasticity of immigration will equal -0.12 .

\section{Immigration and prices}

The wage elasticity in Equation (19) gives the wage impact of immigration in terms of the price of the imported product (i.e., the numeraire). It is also of interest to determine the impact of immigration relative to the price of the domestically produced good. After all, immigration has domestic product price effects both because the wage drops and because immigrants themselves shift the product demand curve outwards ${ }^{16}$. By differentiating Equation (15) with respect to the immigration-induced supply shift, it can be shown that the effect of immigration on the domestic price is:

$$
\frac{d \log p}{d \log L}=\frac{\lambda \eta s_{K}}{(1+\lambda-\delta)-(1-\delta-\eta) s_{K}}-\frac{\eta(1-\phi)\left[\lambda+(1-\delta) s_{L}\right]}{(1+\lambda-\delta)-(1-\delta-\eta) s_{K}} .
$$

Suppose there is product market neutrality. The second term of (25) then vanishes, and immigration has no price effects in the long run $(\lambda=0)$. However, Equation (25) shows that immigration must increase prices as long as the product demand curve is downward sloping $(\eta>0)$ and capital has not fully adjusted. The inflationary effect of immigration is attenuated (and potentially reversed) if $\phi<1$ and product demand does not rise proportionately with the size of the immigrant influx.

The prediction that domestic prices rise at the same time that wages fall seems counterintuitive. However, it is easy to understand the economic factors underlying this result by noting that the derivative in (25) can also be expressed as:

$$
\frac{d \log p}{d \log L}=\eta s_{K}\left(1-\frac{d \log K}{d \log L}\right)-\eta(1-\phi) .
$$

As long as there is product market neutrality, the price of the domestic good must rise whenever capital adjusts by less than the immigration-induced percent shift in 
supply. The intuition is clear: In the absence of full capital adjustment, the immigration-induced increase in domestic product demand cannot be easily met by the existing mix of inputs, raising the price of the domestic product ${ }^{17}$.

An important question, of course, is: what happens to the real wage defined in terms of the price of the domestic product (or $w / p$ )? By combining results from Equations (19) and (25), it is easy to show that:

$$
\dot{w}=\frac{d \log (w / p)}{d \log L}=\frac{-\lambda(1-\delta) s_{K}}{(1+\lambda-\delta)-(1-\delta-\eta) s_{K}}-\frac{\eta(1-\phi)(1-\delta) s_{K}}{(1+\lambda-\delta)-(1-\delta-\eta) s_{K}} .
$$

Note that if the product market neutrality assumption holds, the second term in (27) vanishes and immigration must reduce the real wage as long as capital does not fully adjust. This result does not depend on the relative magnitudes of the elasticities of substitution and product demand. The negative impact of immigration on the real wage is not surprising. After all, immigration reduces the nominal wage and increases the domestic price simultaneously. To simplify the discussion, I will refer to the elasticity in (27) as the real wage elasticity of immigration.

In order to get a sense of the magnitude of the real wage elasticity, it is instructive to refer back to the simplest example: a Cobb-Douglas economy in the short run. Equation (27) collapses to:

$$
\left.\frac{d \log (w / p)}{d \log L}\right|_{\substack{\delta=0 \\ \lambda=\infty}}=-s_{K} .
$$

The short-run real wage elasticity is identical to that implied by the simplest onegood Cobb-Douglas model in Equation (7). Even after the model accounts for the fact that immigrants increase the size of the consumption base proportionately and that immigration-induced price changes move the pre-existing consumers along their product demand curve, the short-run real wage elasticity is still -0.3 .

The theory of factor demand clarifies an important misunderstanding: the oftenheard argument that the outward shift in product demand induced by immigration will somehow return the economy to its pre-immigration equilibrium does not have any theoretical support. Instead, the theory reveals that immigration has an adverse effect on the real wage ${ }^{18}$. Put differently, the number of domestically produced widgets that the typical worker in the receiving country can potentially buy will decline as the result of the immigrant influx-even after one accounts for the fact that immigrants themselves will increase the demand for widgets. And, under some conditions, the decline in the number of widgets that can be purchased is exactly the same as the decline found in the simplest factor demand model that ignores the role of immigrants in the widget product market.

\section{Extensions of the homogeneous labor model}

The model summarized in the previous section incorporates two important restrictions. First, the product demand function for the domestic good $q$ does not depend on the consumer's income; second, the price of good $y$ is fixed (so that the foreign export supply curve for $y$ is perfectly elastic). I now extend the framework by relaxing both of 
these assumptions simultaneously. It is convenient to begin by modeling consumer demand for good $y$. Suppose the typical consumer's demand function for the imported good can be written as:

$$
y_{j}=h_{j} p_{y}^{-\frac{1}{\tau}} p^{\frac{1}{\tau}-1} Z_{j}
$$

where $h_{j}$ is a person-specific shifter detailing a consumer's relative preference for good $y ; p_{y}$ is the price of good $y ; p$ continues to be the price of $\operatorname{good} q$; and $Z_{j}$ is the consumer's income. The consumer's income is equal to $w$ if he is a worker in the domestic economy; $r$ is he is a capitalist in the domestic economy; and $x$ if he is a consumer in the "rest of the world". The weight $h$ may differ among the various types of consumers.

The parameter $\tau$ is positive and is the inverse price elasticity of demand for good $y^{19}$. The demand function in (29) builds in two properties. First, consumers have homothetic preferences (implying that the income elasticity is unity). Second, the demand function is homogeneous of degree zero, so that the three elasticities defined in (29) add up to zero.

The aggregate demand for the imported good is given by:

$$
Y=p_{y}^{-\frac{1}{\tau}} p^{\frac{1}{r}-1}\left(h_{L} C_{L} w+h_{K} C_{K} r+h_{X} C_{X} x\right) .
$$

Let $V_{y}=h_{L} C_{L} w+h_{K} C_{K} r+h_{X} C_{X} x$, the "effective" wealth that determines aggregate demand for the imported good ${ }^{20}$. The inverse demand function for $Y$ can then be written as:

$$
p_{y}=Y^{-\tau} p^{1-\tau} V_{y}^{\tau} .
$$

The aggregate supply curve for $Y$ is given by:

$$
p_{y}=Y^{\varphi},
$$

where $\varphi$ is the inverse elasticity of supply. The equilibrium price of good $y$ is determined by the simultaneous solution of Equations (31) and (32).

The aggregate demand curve for the domestic good $Q$ when there are wealth effects can be derived in an analogous fashion and is given by:

$$
Q=p^{-\frac{1}{\eta}} p_{y}^{\frac{1}{\eta}-1} V_{q},
$$

where $V_{q}=g_{L} C_{L} w+g_{K} C_{K} r+g_{X} C_{X} x$, and measures the effective wealth that determines aggregate demand for the domestic good ${ }^{21}$. The demand function in (33) is also derived from homothetic preferences and is homogeneous of degree zero. By substituting in the expression for the equilibrium price of good $y$, it is possible to solve for the inverse aggregate demand function for the domestic good:

$$
p=Q^{-\hat{\eta}} V_{q}^{\hat{\eta}} V_{y}^{\hat{\varphi}},
$$

where $\hat{\eta}$ and $\hat{\varphi}$ are rescaled values of the parameters $\eta$ and $\phi$, respectively ${ }^{22}$. Analogous to the restrictions in Equation (22), the second-order conditions for the social planner problem now imply that $\hat{\eta}<1$ (which, in turn, implies that $\eta<1$ ). It then follows that $\hat{\varphi}$ must also lie between zero and one. Note that $\hat{\eta}=\eta$ and $\hat{\varphi}=0$ when the supply curve for the imported good is perfectly elastic. 
It is instructive to compare Equation (34) with Equation (15), the aggregate demand function in the model that ignored wealth effects and assumed that the supply of $Y$ was perfectly elastic. In the simpler model, the inverse demand function for $Q$ was $p=Q^{-\eta} C^{\eta}$, and the shifter was simply the (weighted) number of consumers who purchased the domestic good. Even if the supply curve of $Y$ were perfectly elastic (implying $\hat{\phi}=0$ ), the shifter in Equation (34) differs because it depends not only on the number of consumers, but also on their wealth.

The presence of wealth effects implies that the impact of immigration on wages in the domestic labor market now depends on: (a) how immigration changes the size of the consumer base for each of the two goods; and (b) how immigration changes the average income of the consumer base. The first of these effects, of course, is related to the product market neutrality assumption. Suppose that the pay rate to each of the groups that make up the consumer base (i.e., $w, r$, and $x$ ) is held constant. The immigration-induced percent change in the size of the consumer base for the domestic good is given by:

$$
\phi_{q}=\left.\frac{d \log V_{q}}{d \log L}\right|_{w, r, x}=\varepsilon_{D}^{q} s_{L} \frac{d \log C_{L}}{d \log L}+\varepsilon_{D}^{q} s_{K} \frac{d \log C_{K}}{d \log L}+\left(1-\varepsilon_{D}^{q}\right) \frac{d \log C_{X}}{d \log L},
$$

where $\varepsilon_{D}^{q}=1-\left(g_{X} C_{X} x / V_{q}\right)$, the share of total expenditures in good $q$ that is attributable to domestic consumers. The elasticity $\phi_{q}$, of course, is the counterpart of the elasticity $\phi$ in the simpler model above.

The impact of immigration on the size of the consumer base for the imported good is:

$$
\phi_{y}=\left.\frac{d \log V_{y}}{d \log L}\right|_{w, r, x}=\varepsilon_{D}^{y} s_{L} \frac{d \log C_{L}}{d \log L}+\varepsilon_{D}^{y} s_{K} \frac{d \log C_{K}}{d \log L}+\left(1-\varepsilon_{D}^{y}\right) \frac{d \log C_{X}}{d \log L},
$$

where $\varepsilon_{D}^{y}=1-\left(h_{X} C_{X} x / V_{y}\right)$, the share of total expenditures in good $y$ that is attributable to domestic consumers. If much of the output of the domestic good is consumed domestically, while much of the output of the imported good is consumed abroad, it would be reasonable to expect that the elasticity $\phi_{q}$ would be relatively large (perhaps nearing one), while the elasticity $\phi_{y}$ would be relatively small.

One final issue needs to be addressed before I can calculate the wage elasticity in the domestic labor market. It is clear from the definitions of $V_{q}$ and $V_{y}$ that the immigrationinduced wealth effect will also depend on what happens to $x$, the pay rate in the foreign economy. For simplicity, I assume that immigration (though it may be large relative to the size of the domestic workforce) is small relative to the size of the workforce in the rest of the world. Hence I ignore any potential effects on consumer demand (and the domestic labor market) through the change in the level of foreign income $x$.

The mathematical appendix describes the solution of this model. The resulting expressions are more complex because of the rapidly exploding number of elasticities (and income shares) required to describe all the feedback effects in the model. To simplify, I consider the case of a Cobb-Douglas production function. Further, I restrict the 
discussion to the impact of immigration on the real wage defined by $w / p$. The real wage elasticity in the expanded model is then given by:

$$
\left.\frac{d \log (w / p)}{d \log L}\right|_{\delta=0}=\frac{-\lambda\left(1-\hat{\eta} \varepsilon_{D}^{q}-\hat{\varphi} \varepsilon_{D}^{y}\right) s_{K}}{\Delta}+\frac{\hat{\eta}\left(\phi_{q}-1\right)+\hat{\varphi} \phi_{y}}{\Delta},
$$

where $\Delta=(1+\lambda)\left[1-\hat{\eta} \varepsilon_{D}^{q} s_{L}-\hat{\varphi} \varepsilon_{D}^{y} s_{L}\right]-\left[(1-\hat{\eta})+\hat{\eta} \lambda \varepsilon_{D}^{q}+\hat{\varphi} \lambda \varepsilon_{D}^{y}\right] s_{K}$.

It is instructive to compare the real wage elasticity in Equation (37) with the analogous expression in (27), which ignored wealth effects and assumed the supply of the imported good $y$ was perfectly elastic ${ }^{23}$. For simplicity, suppose that "generalized" product market neutrality holds, so that the second term in both Equation (27) and Equation (37) vanishes ${ }^{24}$. It is easy to see that the numerator of (37) contains the additional term $\lambda\left(\hat{\eta} \varepsilon_{D}^{q}+\hat{\varphi} \varepsilon_{D}^{y}\right) s_{K}$. This additional term represents two distinct scale effects induced by the changing wealth of consumers. Both of these scale effects are positive, so that they weaken the adverse labor market impact of immigration as long as capital has not fully adjusted.

The first wealth effect (the term multiplied by $\hat{\eta}$ ) arises because immigration necessarily increases average income in the domestic economy. In other words, as is typical in this type of model, the losses incurred by workers are more than made up by the gains accruing to capitalists (Borjas 1995). The wealth effect generated by the higher average income increases demand for the domestically produced good, increases the demand for labor, and helps to attenuate the adverse labor market impact of immigration. The second wealth effect (the term multiplied by $\hat{\varphi}$ ) arises because immigration also generates increased demand for the imported good $y$. If the supply curve of the imported good is not perfectly elastic, however, the wealth effect increases the price of the imported good, encouraging consumers to switch back to the domestic good, further attenuating the adverse impact of immigration on the domestic wage.

Despite the additional complexity, Equation (37) yields three unambiguous results as long as there is generalized product market neutrality:

1. The real wage elasticity is zero in the long run (i.e., when $\lambda=0$ ).

2. As shown in the mathematical appendix, the real wage elasticity in (37) must be negative as long as there is incomplete capital adjustment ${ }^{25}$. In other words, the scale effects generated by the immigration-induced changes in consumer demand can never be sufficiently strong to reverse the direct adverse impact of immigration in the domestic labor market.

3. The short-run effect of immigration is given by:

$$
\left.\frac{d \log (w / p)}{d \log L}\right|_{\substack{\delta=0 \\ \lambda=\infty}}=-s_{K}
$$

Remarkably, we have come full circle to the beginning of the analysis (see Equation (7)). The short-run real wage elasticity of immigration is still -0.3 , even after the model accounts for all the feedback possibilities introduced by wealth effects in the product market and inelastic supply of the imported good ${ }^{26}$. 


\section{Heterogeneous labor}

The presence of heterogeneous labor implies that the impact of immigration on the wage of any single group of workers depends on how immigration affects the supply of every group of workers. In both theoretical and empirical work, therefore, the need arises to reduce the dimensionality of the problem, typically by limiting the types of permissible cross-effects among inputs. The need for tractability becomes more acute if one wishes to allow for the presence of heterogeneous labor in the general equilibrium model presented in the previous sections.

The nested CES framework is relatively tractable and has become popular in the immigration literature $^{27}$. In particular, think of the labor input $L$ as a labor aggregate-an agglomeration of workers belonging to different skill groups. The Armington aggregator that combines different labor inputs is given by:

$$
L=\left[\theta_{1} L_{1}^{\beta}+\theta_{2} L_{2}^{\beta}\right]^{1 / \beta}
$$

where $L_{i}$ gives the number of workers in group $i$; the elasticity of substitution between groups 1 and 2 is defined by $\sigma_{12}=1 /(1-\beta)$, with $\beta \leq 1$; and $\theta_{1}+\theta_{2}=1$. Although the exposition uses two different labor inputs, it will be evident that all of the results extend to any number of inputs.

Immigrants can shift the supply of either of the two groups. Let $m_{i}=d L_{i} / L_{i}$ give the immigration-induced percent supply shift for group $i$. It is easy to show that the percent shift in the aggregate labor input is given by:

$$
d \log L=\frac{s_{1}}{s_{L}} m_{1}+\frac{s_{2}}{s_{L}} m_{2}=\bar{m},
$$

where $s_{i}$ is the share of income accruing to group $i$, and $s_{L}=s_{1}+s_{2}$. Equation (40) reveals an interesting property of the nested CES framework: It is not necessary to know the value of the elasticity of substitution $\sigma_{12}$ to calculate the size of the immigrationinduced shift in the labor aggregate $L$. All of the pertinent information is contained in the income shares accruing to the various skill groups.

The modeling of product demand in a market with heterogeneous labor requires particular attention as workers differ in their productivity and inevitably have different resources when they enter the product market. It is easier to grasp the intuition by considering the simpler version of the general equilibrium model presented in Section 3 that ignores wealth effects and assumes that the supply of the imported good is perfectly elastic ${ }^{28}$.

In that framework, the inverse product demand function was given by $p=C^{\eta} Q^{-\eta}$, where the effective number of consumers for the domestic good is $C=g_{L} C_{L}+g_{K} C_{K}+$ $g_{x} C_{X}$. I use the same market demand function in the heterogeneous labor model. The fact that workers are heterogeneous-and that this heterogeneity affects aggregate demand-can be easily captured by positing that $C_{L}=f(L)$. Hence the shifter in the inverse product demand function depends on the efficiency units-adjusted number of workers. Those workers who are more productive and have higher wages "count" proportionately more in the aggregation.

The model, therefore, consists of the inverse product market demand function in Equation (15), the aggregate production function in Equation (16), the inverse supply 
curve of capital in Equation (17), and the Armington aggregator in Equation (39). The condition that the wage of input $i$ equals the group's value of marginal product is:

$$
w_{i}=\left[(1-\alpha) C^{\eta} Q^{1-\delta-\eta} L^{\delta-1}\right] \theta_{i} L^{1-\beta} L_{i}^{\beta-1}
$$

It is obvious that the marginal productivity condition for the price of capital is identical to that found in the homogeneous labor model in Equation (18a). Equally important, the marginal productivity condition for skill group $i$ in Equation (41) is very similar to that obtained in the homogeneous labor model in Equation (18b). In fact, the bracketed term in (41) is identical to the value of marginal product of labor in the homogeneous labor case. The fact that there are now two different skill groups simply adds the multiplicative term that appears to the right of the bracket.

Define $w$ to be equal to the bracketed term in (41). By differentiating Equation (41) and using the supply shift defined in (40), it is easy to show that the effect of immigration on the wage of group $i$ is given by:

$$
\begin{aligned}
d \log w_{i} & =d \log w+(1-\beta) d \log L+(\beta-1) d \log L_{i} \\
& =d \log w+(1-\beta)\left(\bar{m}-m_{i}\right)
\end{aligned}
$$

Equation (42) has a number of important properties. Suppose, for instance, that we are interested in the impact of immigration on the relative wage of the two skill groups. The distributional effect is given by:

$$
d \log w_{1}-d \log w_{2}=-\frac{1}{\sigma_{12}}\left(m_{1}-m_{2}\right)
$$

Equation (43) establishes an important property of the nested CES framework: the impact of immigration on relative wages depends only on the elasticity of substitution between the two groups and is proportional to the relative supply shift. If the two groups are perfect substitutes, immigration has no relative wage effect. If the two groups are imperfect substitutes, the group that experiences the larger supply shock will always experience a decline in its relative wage ${ }^{29}$. None of the "fundamentals" that play a role in the homogeneous labor model (i.e., $\eta, \lambda, \sigma$, and $\phi$ ) help determine the distributional impact. For instance, the relative wage effect does not depend on the extent to which capital adjusts to the immigrant influx ${ }^{30}$.

In addition to any distributional effects, immigration also has an impact on the aggregate wage level, where $d \log \bar{w}=\left(s_{1} d \log w_{1}+s_{2} d \log w_{2}\right) / s_{L}$. Equation (42) implies that:

$$
d \log \bar{w}=d \log w
$$

In short, the impact of immigration on the average wage in a model with heterogeneous labor is identical to the impact of immigration on the wage in a model with homogeneous labor, as given by Equation $(19)^{31}$. For instance, in a Cobb-Douglas world with perfectly elastic product demand, the homogeneous labor model predicts that the wage elasticity of immigration will lie between -0.3 (in the short run) and 0.0 (in the long run). Even with heterogeneous labor, it must still be the case that the wage 
elasticity of immigration is between -0.3 and 0.0. In an important sense, the average wage effect has been "pre-determined" (by the values of the fundamentals $\eta, \lambda, \sigma$, and $\phi)$, and is independent of whatever complementarities may or may not exist among labor inputs in the production process.

The imperfect substitution among skill groups helps to position the wage effect for each of the groups around this pre-determined average wage effect. Suppose, for instance, that an immigrant influx doubles the size of the (efficiency-units adjusted) workforce. In a Cobb-Douglas world, the short-run wage impact on one group will typically be larger than -0.3 , while the wage impact on the other group will typically be smaller than -0.3 . For a given $\sigma_{12}$, the specific deviations from -0.3 will depend on: a) the disparity in the supply shocks experienced by the two groups; and b) the income shares of the groups, since the weighted average of the two wage effects has to be identically equal to -0.3 . Put differently, the constraints imposed by factor demand theory and by the functional form of the nested CES framework greatly restrain the structure of immigration wage effects that can possibly be estimated by any data.

Moreover, even a generalization of the model that would instead specify a linear homogenous production function at the top level of the nesting introduces equally arbitrary numerical restrictions. The linear homogeneity assumption implies that the long-run average wage impact must be zero, so that one group will typically gain slightly and the other group will typically lose.

It is worth emphasizing these insights in a different way. Numerous published simulations claim that data analysis based on structural factor demand models implies that the impact of immigration on the wage of the average worker is $x$ percent, or that the impact on the wage of the average worker in a particular skill group is $y$ percent. These simulations uniformly use a linear homogeneous (and often a Cobb-Douglas) aggregate production function. As we have seen, these functional form assumptions build in numerically what the mean wage effect of immigration must have been. The (absolute) long-run wage effects reported by these studies have nothing to do with the underlying data; they are simply regurgitating the constraints imposed by factor demand theory (i.e., the average wage effect must be zero). And even the short-run wage effects are simply spewing out the numerical implications of the presumed Cobb-Douglas technology.

\section{Imperfect substitution between immigrants and natives}

Some recent studies (Card 2009; Ottaviano and Peri 2012; Manacorda et al. 2012) argue that immigrants and natives within a skill group are imperfect substitutes-and that the resulting complementarities may greatly attenuate the adverse wage impact of immigration on the pre-existing workforce ${ }^{32}$. These models typically expand the nested CES framework by adding yet another level that aggregates the contribution of immigrants and natives in skill group $i$ :

$$
L_{i}=\left[\rho_{N} N_{i}^{\gamma}+\rho_{F} F_{i}^{\gamma}\right]^{1 / \gamma},
$$

where $N_{i}$ and $F_{i}$ give the number of native and foreign-born workers in skill group $i$, respectively; the elasticity of substitution between native and immigrant workers is $\sigma_{N F}=1 /(1-\gamma)$, with $\gamma \leq 1$; and $\rho_{N}+\rho_{F}=1$. 
There are now separate marginal productivity conditions for native and immigrant workers. For skill group $i$, these conditions are:

$$
\begin{aligned}
& w_{i}^{N}=\left[(1-\alpha) C^{\eta} Q^{1-\delta-\eta} L^{\delta-1}\right]\left(\theta_{i} L^{1-\beta} L_{i}^{\beta-1}\right)\left(\rho_{N} L_{i}^{1-\gamma} N_{i}^{\gamma-1}\right), \\
& w_{i}^{F}=\left[(1-\alpha) C^{\eta} Q^{1-\delta-\eta} L^{\delta-1}\right]\left(\theta_{i} L^{1-\beta} L_{i}^{\beta-1}\right)\left(\rho_{F} L_{i}^{1-\gamma} F_{i}^{\gamma-1}\right),
\end{aligned}
$$

where $w_{i}^{N}$ and $w_{i}^{F}$ give the wage of native and immigrant workers in group $i$, respectively.

By comparing Equations (46a) and (46b) with Equation (41), it is obvious that the presence of within-group imperfect substitution simply adds yet another multiplicative term to the marginal productivity conditions. The bracketed term still represents the "average" wage in the economy, aggregated across all skill groups. This is the wage level determined by the factor demand theory parameters discussed in Section 3. The product of this bracketed term and $\theta_{i} L^{1-\beta} L_{i}^{\beta-1}$ gives Equation (41), the mean wage for group $i$.

The multiplicative separability property allows us to easily assess the potential importance of immigrant-native complementarities in the evolution of the wage structure. Differentiating Equations (46a) and (46b) gives the impact of a supply shift on the wage of native and immigrant workers in group $i$ :

$$
\begin{aligned}
& d \log w_{i}^{N}=d \log w+(1-\beta)\left[d \log L-d \log L_{i}\right]+(1-\gamma)\left[d \log L_{i}-d \log N_{i}\right] . \\
& d \log w_{i}^{F}=d \log w+(1-\beta)\left[d \log L-d \log L_{i}\right]+(1-\gamma)\left[d \log L_{i}-d \log F_{i}\right] .
\end{aligned}
$$

Suppose a supply shock changes the number of immigrants in each of the skill groups, but leaves the number of native workers unchanged. Let $\bar{m}$ be the immigration-induced percent change in the efficiency units-adjusted size of the workforce, and $m_{i}$ be the percent change in the size of the efficiency units-adjusted workforce in skill group $i$. The "averaging property" in Equation (40) implies that these supply shifts are given by:

$$
\begin{aligned}
& d \log L=\bar{m}=\frac{s_{1}}{s_{L}} m_{1}+\frac{s_{2}}{s_{L}} m_{2}, \\
& d \log L_{i}=m_{i}=\frac{s_{i}^{F}}{s_{i}} f_{i},
\end{aligned}
$$

where $s_{i}^{F}$ is the share of income accruing to immigrants in group $i$ (with $s_{i}^{F}+s_{i}^{N}=s_{i}$ ); and $f_{i}=d F_{i} / F_{i}$, the percent increase in the size of the foreign-born workforce in that group.

The presence of within-group imperfect substitution can have important consequences for within-group inequality. The relative wage effect is:

$$
d \log w_{i}^{F}-d \log w_{i}^{N}=-\frac{1}{\sigma_{N F}} f_{i} .
$$

The distributional effect in (51) depends only on the elasticity of substitution between immigrants and natives and on the size of the increase in group $i$ 's foreign-born workforce. In the nested CES framework, the value of the elasticity $\sigma_{N F}$ does not have any other implications. For instance, consider the impact of immigration on the average 
wage of pre-existing workers in group $i$, where $d \log \bar{w}_{i}=\left(s_{i}^{N} d \log w_{i}^{N}+s_{i}^{F} d \log w_{i}^{F}\right) / s_{i}$. It is easy to show that:

$$
d \log \bar{w}_{i}=d \log w+(1-\beta)\left(\bar{m}-m_{i}\right),
$$

which is identical to Equation (42), the implied wage effect in the simpler model that assumed that immigrants and natives in a skill group were perfect substitutes. Put differently, the value of $\sigma_{N F}$ does not influence the shape of the wage distribution across skill groups. It is trivial to move up yet another level in the CES nesting and calculate the average wage effect across skill groups. This exercise would again yield equation (44), so that the average wage effect would be independent from both $\sigma_{12}$ and $\sigma_{N F}$.

The nested CES framework, therefore, imposes an important restriction on any study of the distributional impact of immigration: The wage impact at a particular level of the nesting depends only on the elasticities that enter the model at or above that level, and does not depend on any of the elasticities that enter the model below that level. Hence the impact of immigration on the aggregate wage does not depend on the value of the elasticity of substitution across skill groups or on the presence or absence of within-group complementarities. Similarly, the impact of immigration on the wage of a particular skill group is unaffected by within-group complementarities between immigrants and natives.

\section{Summary}

This paper presents the analytics that underlie the study of the wage effects of immigration. The general equilibrium framework reveals that the effect of immigration on the mean wage depends on the parameters that Marshall first identified in his famous rules of derived demand (i.e., the elasticity of substitution between labor and capital, the supply elasticity of capital, the elasticity of product demand, and labor's share of income). The immigration context also shows the importance of an additional parameter: the impact of immigration on the size of the consumer base relative to its impact on the size of the workforce. The analysis reveals that the short-run wage effect of immigration can be negative in a wide array of possible scenarios, and that even the long run effect of immigration may be negative if the impact of immigration on the potential size of the consumer base is smaller than its impact on the size of the workforce. Interestingly, however, the analysis also demonstrates that both the short- and long-run effects could be positive if immigration increases the size of the consumer base for the domestic product dramatically.

The simplicity of the factor demand framework (combined with specification restrictions on the production technology) also leads to closed-form solutions of the wage effect of immigration. As a result, it is easy to conduct back-of-the-envelope calculations of the predicted wage effect. The constraints imposed by the theory of labor demand can then be used to assess the plausibility of the many contradictory claims that are often made about how immigration affects the wage structure in sending and receiving countries.

The theoretical framework presented in this paper can be extended in a number of ways. For instance, the domestic economy can produce different types of goods (some may be labor-intensive and some may be capital-intensive; some may be traded and others non-traded). An immigration-induced supply shift would induce flows of resources among the various sectors. It would be of interest to determine whether the aggregate wage 
impact of immigration (i.e., the impact that averages out the wage effect across sectors) is affected by the leveraging possibilities introduced by the multi-sector framework.

The paper also points to a new direction for empirical research. The theoretical framework, after all, highlights the importance of determining how immigration changes the relative number (and wealth) of consumers in the receiving country. The theory clearly demonstrates that an imbalance between the impact of immigration on the size of the consumer base and its impact on the size of the workforce can generate permanent wage effects. It seems, therefore, that the consumption behavior of immigrants is a topic ripe for empirical investigation.

\section{Endnotes}

${ }^{1}$ Hicks (1932) gives the classic presentation of Marshall's rules of derived demand. Ewerhart (2003) and Kennan (1998) provide much simpler (and clearer) derivations.

${ }^{2}$ For instance, Wagner (2009) represents the first to attempt to isolate empirically the substitution and scale effects of an immigration-induced supply shift.

${ }^{3}$ The elasticity of complementarity is the dual of the elasticity of substitution. Hamermesh (1993) presents a detailed discussion of the properties of the elasticity of complementarity; see also Hicks (1970) and Sato and Tetsunori (1973).

${ }^{4}$ The labor supply of the pre-existing workforce is assumed to be perfectly inelastic. The immigration-induced supply shift can then be illustrated as an outward shift of a vertical supply curve.

${ }^{5}$ The elasticities of complementarity implied by the CES function are $c_{K L}=(1-\delta)$ and $c_{L L}=-(1-\delta)\left(s_{K} / s_{L}\right)$.

${ }^{6}$ The introduction of a second good is crucial if one wishes to examine how immigration affects aggregate product demand and prices. If there were only one good in the economy, all units of that good are sold regardless of the price. The framework developed below is related to the standard $2 \times 2 \times 2$ model in international trade (Dixit and Norman 1980).

${ }^{7}$ The definition of the goods implies that immigration and trade are complements since there is complete specialization of goods production. If immigration and trade were substitutes, as in Mundell's (1957) classic analysis, there may then be factor price equalization across countries. Immigration would have no wage effects and would only alter the distribution of outputs as described by the Rybczynski Theorem. I do not address the long-running debate over whether immigration and trade are complements or substitutes. The model presented below is instead designed to depict an economic environment where wage differences exist and induce labor to migrate internationally. See Kennan (2013) for an alternative approach that allows for factor price equalization.

${ }^{8}$ Since there are no wealth effects, it is not necessary to specify what income $Z$ is for each of the groups. I will give a precise definition when I introduce wealth effects below.

${ }^{9}$ As will be shown below, the answer to this question plays a crucial role in determining the wage impact of immigration. Nevertheless, it has only been addressed empirically by the pioneering work in Olney (2013).

${ }^{10}$ The issue of whether immigrants are "new" consumers can be approached in a number of ways. It could be argued, for instance, that immigration substantially 
increases the number of domestic consumers (through the increase in $C_{L}$ ), and leads only to a trivial decline in the relative number of consumers from abroad. Alternatively, it may be that immigrants change their preferences for the domestic good once they reside in their new home. Even though the increase in $C_{L}$ may be completely offset by the decline in $C_{X}$, the weight determining the post-migration demand of the immigrants for the domestic good increases from $g_{X}$ to $g_{L}$. Moreover, immigration will also change the number of capitalist-consumers. The value of the elasticity $\phi$ gives the net impact of all the possible immigration-induced changes in the size of the consumer base.

${ }^{11}$ It is interesting to note that the expression in Equation (19), when evaluated at $\phi=0$, is equal to the reciprocal of the Hicks-Marshall formula that defines the labor demand elasticity ( $d \log L / d \log w$ ) in the generic derivation of Marshall's rules; see, for example, Kennan (1998, p. 6).

${ }^{12}$ In particular, $(1+\lambda-\delta)-(1-\delta-\eta) s_{K}=\lambda+(1-\delta) s_{L}+\eta s_{K}$. The denominator is strictly positive since $\eta>0$.

${ }^{13}$ Benhabib (1996) models the political economy tradeoffs that determine the optimal choice of an immigration policy.

${ }^{14}$ The second-order conditions would also be satisfied if cost $h$ was not constant, but increased with the number of immigrants. Note also that the second-order conditions in (22) imply that the social planner (like a monopolist) chooses an equilibrium point where product demand is elastic.

${ }^{15}$ These conclusions, of course, require that the deviation from product market neutrality continue indefinitely, regardless of how long immigrants have been in the receiving country.

${ }^{16}$ Recent studies of the price effect of immigration include Lach (2007), Cortes (2008), and Saiz (2007).

${ }^{17}$ The response of the capital stock to the immigrant influx is:

$$
\frac{d \log K}{d \log L}=\frac{(1-\delta)-(1-\delta-\eta) s_{K}}{(1+\lambda-\delta)-(1-\delta-\eta) s_{K}}-\frac{\eta(1-\phi)}{(1+\lambda-\delta)-(1-\delta-\eta) s_{K}} .
$$

Note that if the product market neutrality assumption holds, the percent shift in the capital stock will be a fraction (between 0 and 1 ) of the immigration-induced percent shift in the size of the workforce.

${ }^{18}$ There are alternative ways of defining the real wage. For instance, one can define a price index $\bar{p}=p_{y}^{1-\mu_{D}} p^{\mu_{D}}$, where $p_{y}$ is the price of good y (which is fixed at 1), and $\mu_{D}$ is the share of income that is spent in good $y$ in the domestic economy. Holding constant the share $\mu_{D}$, the resulting real wage elasticity in the case of product market neutrality is:

$$
\frac{d \log (w / \bar{p})}{d \log L}=\frac{-\lambda\left[1-\delta-\eta\left(1-\mu_{D}\right)\right] s_{K}}{(1+\lambda-\delta)-(1-\delta-\eta) s_{K}}
$$

which must be negative if the second-order conditions in Equation (22) hold.

${ }^{19}$ Goods $q$ and $y$ are gross substitutes or gross complements depending on whether $\mathrm{\tau}$ is less than or greater than 1 , respectively.

${ }^{20}$ The simplifying assumption that a domestic consumer's wealth equals his income (i.e., $w$ or $r$ ) implies that the number of worker-consumers $C_{L}$ must equal the number 
of workers $L$, and that the number of capitalist consumers $C_{K}$ equals the capital stock $K$, so that each capitalist-consumer owns one unit of capital.

${ }^{21}$ The solution of the model is greatly simplified if there is a proportional relation between the weighting factors for the domestic and imported goods for both workers and capitalists. In particular, I assume that $h_{L}=v g_{L}$ and $h_{K}=v g_{K}$. The proportionality property allows expressing the various elasticities in terms of labor's share of income, $s_{L}$.

${ }^{22}$ The rescaled elasticities are defined as $\hat{\eta}=\frac{\eta}{1-\varphi^{*}(1-\tau)(1-\eta)}$ and $\hat{\varphi}=\frac{\varphi^{*} \tau(1-\eta)}{1-\varphi^{*}(1-\tau)(1-\eta)}$, where $\varphi^{*}=\frac{\varphi}{\varphi+\tau}$.

${ }^{23}$ In the special case where there are no wealth effects and the supply curve of the imported good is not perfectly elastic, all the terms involving the share $\varepsilon$ in equation (37) would drop out.

${ }^{24}$ The "generalized" form of product market neutrality required in Equation (37) is $\hat{\eta}\left(\phi_{q}-1\right)+\hat{\varphi} \phi_{y}=0$.

${ }^{25}$ The proof uses the fact that the rescaled elasticities $\hat{\eta}$ and $\hat{\varphi}$ are both positive and less than one. It is easy to verify that their sum is also less than one. To show that the sign of the numerator in (37) must be negative, simply evaluate the numerator at the point where the income shares in the expression take on the value of one, so that the scale effects are at their maximum value. Using the same numerical properties of the rescaled elasticities, it can also be shown that the denominator must be positive.

${ }^{26}$ The real wage can also be defined as the ratio of $w$ to a price index $\bar{p}=p_{y}^{1-\varepsilon_{D}^{q}} p^{\varepsilon_{D}^{q}}$, where the consumption shares in the exponents are treated as constants. A sufficient condition for the short-run real wage elasticity to be negative is that goods $q$ and $y$ be gross substitutes (i.e., $\mathrm{\tau}<1$ ).

${ }^{27}$ Bowles (1970) introduced the nested CES framework into the labor demand literature. More recently, it was used by Card and Lemieux (2001) to analyze the evolution of the wage structure, and by Borjas (2003) to estimate the wage impact of immigration. As an example of the extreme restrictions that the nested CES framework imposes on the number of "permissible" cross-effects, consider the empirical analysis in the Borjas (2003) study. It uses 32 distinct skill groups in the workforce (4 education groups and 8 age groups), and capital. There are then a total of 1,089 own- and crossgroup effects to estimate. The symmetry restrictions implied by factor demand theory reduce this number to 561. The nested CES framework assumes that all of these crosseffects can be described in terms of three elasticities of substitution.

${ }^{28}$ It is worth emphasizing, however, that all of the results presented below carry through to the more general model with wealth effects and an upward sloping foreign export supply curve.

${ }^{29}$ The implication that relative wage effects are proportional to relative supply shifts suggests that one should be skeptical when evaluating the empirical evidence reported in the literature. After all, it is easy to manipulate results by defining skill groups in ways that either accentuate the relative supply shift or that mask it. This point was first illustrated in Borjas et al. (1997). Their simulations show that the wage effect of immigration in the United States is much greater when one compares high school dropouts to the rest of the workforce than when one compares high school "equivalents" to the rest of the workforce. The difference arises because "high school equivalents" typically 
include both high school dropouts and high school graduates. Although there has been a substantial influx of foreign-born high school dropouts, their numerical importance is obviously very different if the competing group consists only of native high school dropouts or if it also includes the millions of native high school graduates.

${ }^{30}$ This implication of the model, of course, is a direct consequence of the assumed nested CES technology.

${ }^{31}$ Note, however, that the definition of the supply shift is slightly different. In the homogeneous labor context, the supply shift is measured by the percent increase in the size of the workforce, while in the nested CES framework it is measured by the percent increase in the efficiency units-adjusted size of the workforce.

${ }^{32}$ As pointed out by Borjas et al. 2008, 2012, however, the original Ottaviano and Peri (2005) study made sampling decisions that contaminated the analysis. Most conspicuous, Ottaviano and Peri classified millions of native-born currently enrolled high school juniors and seniors as "high school dropouts." The simple exclusion of these students turns their estimate of the elasticity of substitution from about 5 to near infinity. In the published version of their paper, Ottaviano and Peri (2012) report a far higher value of the relevant elasticity of substitution than in their initial working paper.

\section{Mathematical appendix}

\section{Derivation of Equation (19)}

The mathematical derivation is greatly simplified by following the approach in Kennan (1998). First, note that the value of marginal product condition for labor can be written as:

$$
\frac{w}{p}=(1-\alpha) Q^{1-\delta} L^{\delta-1}
$$

By substituting the inverse product demand curve into (A1), it is easy to show that:

$$
\log w=\eta \log C+\log (1-\alpha)+(1-\eta-\delta) \log Q+(\delta-1) \log L .
$$

Differentiating with respect to the immigrant supply shift yields:

$$
\frac{d \log w}{d \log L}=\eta \phi+(1-\eta-\delta) \frac{d \log Q}{d \log L}+(\delta-1) .
$$

Note that the ratio of input prices in a CES technology can be written as a simple function of the ratio of input quantities. In particular:

$$
\frac{w}{r}=\frac{(1-\alpha) L^{\delta-1}}{\alpha K^{\delta-1}} .
$$

Differentiating this expression, while accounting for the fact that $r=K^{\lambda}$, yields:

$$
\frac{d \log K}{d \log L}=\frac{1}{1+\lambda-\delta}\left(\frac{d \log w}{d \log L}+(1-\delta)\right) .
$$

Finally, the CES production function implies that:

$$
\frac{d \log Q}{d \log L}=s_{K} \frac{d \log K}{d \log L}+s_{L}
$$

Equation (19) can be derived by substituting equations (A5) and (A6) into (A3). 


\section{The social planner problem}

The maximization problem faced by the social planner is:

$$
\operatorname{Max} \Omega=p Q-F h=C^{\eta} Q^{1-\eta}-F h .
$$

Suppose that there is product market neutrality. Without loss of generality, let $C=L$. The first-order condition that determines the optimal number of immigrants is:

$$
\frac{\partial \Omega}{\partial F}=\eta L^{\eta-1} Q^{1-\eta}+(1-\alpha)(1-\eta) L^{-(1-\delta-\eta)} Q^{1-\delta-\eta}-h=0 .
$$

The second order condition is given by:

$$
\frac{\partial^{2} \Omega}{\partial F^{2}}=-\eta(1-\eta) L^{\eta-2} Q^{1-\eta} s_{K}-(1-\eta)(1-\delta-\eta)(1-\alpha) L^{\delta+\eta-2} Q^{1-\delta-\eta} s_{K}<0 .
$$

Sufficient conditions for (A9) to hold are $(1-\eta)>0$ and $(1-\delta-\eta)>0$.

\section{The extended model}

Equation (34) in the text shows that the aggregate demand function for the domestic good (after solving out the equilibrium price of good $y$ ) is:

$$
p=Q^{-\hat{\eta}} V_{q}^{\hat{\eta}} V_{\mathrm{y}}^{\hat{\phi}},
$$

where $V_{q}=g_{L} C_{L} w+g_{K} C_{K} r+g_{X} C_{X} x$, and $V_{y}=h_{L} C_{L} w+h_{K} C_{K} r+h_{X} C_{X} x$. The weights for domestic consumers in the demand for the imported and domestic goods are assumed to be proportional, so that $h_{L}=v g_{L}$ and $h_{K}=v g_{K}$. The rescaled elasticities in this aggregate demand function are defined by:

$$
\begin{aligned}
& \hat{\eta}=\frac{\eta}{1-\varphi^{*}(1-\tau)(1-\eta)}, \\
& \hat{\varphi}=\frac{\varphi^{*} \tau(1-\eta)}{1-\varphi^{*}(1-\tau)(1-\eta)}, \\
& \varphi^{*}=\frac{\varphi}{\varphi+\tau} .
\end{aligned}
$$

The inverse demand function in Equation (A10) only makes economic sense (i.e., price depends negatively on quantity and positively on income) if $\hat{\eta}>0$. As a result, the denominator of (A11) must be positive. The second-order conditions for the social planner problem in this extended model will be satisfied if $\hat{\eta}<1$. By using the definition in (A11), it is easy to demonstrate that the restriction that $\hat{\eta}<1$ also implies that $\eta$ is less than 1 . Using these properties, it then follows that $\hat{\varphi}$ must also lie between 0 and 1 . These numerical restrictions will be used below.

Suppose the production function is Cobb-Douglas, with $Q=K^{\alpha} L^{1-\alpha}$. Using (A10), one can then differentiate the marginal productivity condition to obtain:

$$
\frac{d \log w}{d \log L}=-\hat{\eta} \frac{d \log Q}{d \log L}+\hat{\eta} \frac{d \log V_{q}}{d \log L}+\hat{\varphi} \frac{d \log V_{y}}{d \log L}+\alpha \frac{d \log K}{d \log L}-\alpha
$$


The wage elasticity depends on how the effective wealth variables $V_{q}$ and $V_{y}$ change as a result of the immigration-induced supply shift. It is easy to show that:

$$
\begin{gathered}
\frac{d \log V_{q}}{d \log L}=\frac{g_{L} C_{L} w}{V_{q}} \frac{d \log C_{L}}{d \log L}+\frac{g_{K} C_{K} r}{V_{q}} \frac{d \log C_{K}}{d \log L}+\frac{g_{X} C_{X} x}{V_{q}} \frac{d \log C_{X}}{d \log L} \\
+\frac{g_{L} C_{L} w d \log w}{V_{q}} \frac{g_{K} C_{K} r}{d \log L}+\frac{d \log r}{V_{q}} \frac{g^{\prime} \log L}{}
\end{gathered}
$$

where I assume that immigration is sufficiently "small" to leave $x$ (i.e., average income in the "rest of the world") unchanged. The share of total consumption attributable to domestic labor or capital must equal the respective income share. Further, the proportionality property between the weights $g$ and $h$ for domestic consumers implies that Equation (A15) can be rewritten as:

$$
\begin{gathered}
\frac{d \log V_{q}}{d \log L}=\varepsilon_{D}^{q} S_{L} \frac{d \log C_{L}}{d \log L}+\varepsilon_{D}^{q} s_{K} \frac{d \log C_{K}}{d \log L}+\left(1-\varepsilon_{D}^{q}\right) \frac{d \log C_{X}}{d \log L} \\
+\varepsilon_{D}^{q} s_{L} \frac{d \log w}{d \log L}+\varepsilon_{D}^{q} s_{K} \frac{d \log r}{d \log L} .
\end{gathered}
$$

Note that the first three terms of (A16) define the elasticity $\phi_{q}$ in Equation (35).

Using an analogous strategy, it can be shown that the change in the effective wealth determining aggregate demand for good $y$ is:

$$
\begin{gathered}
\frac{d \log V_{y}}{d \log L}=\varepsilon_{D}^{y} S_{L} \frac{d \log C_{L}}{d \log L}+\varepsilon_{D}^{y} s_{K} \frac{d \log C_{K}}{d \log L}+\left(1-\varepsilon_{D}^{y}\right) \frac{d \log C_{X}}{d \log L} \\
+\varepsilon_{D}^{y} s_{L} \frac{d \log w}{d \log L}+\varepsilon_{D}^{y} S_{K} \frac{d \log r}{d \log L} .
\end{gathered}
$$

The first three terms of (A17) define the elasticity $\phi_{y}$ in Equation (36).

The substitution of Equations (A5), (A6), (A16) and (A17) into Equation (A14) yields:

$$
\frac{d \log w}{d \log L}=\frac{-\lambda(1-\hat{\eta}) s_{k}+\hat{\eta} \lambda \varepsilon_{D}^{q} s_{K}+\hat{\varphi} \lambda \varepsilon_{D}^{y} s_{K}+(1+\lambda)\left[\hat{\eta}\left(\phi_{q}-1\right)+\hat{\varphi} \phi_{y}\right]}{(1+\lambda)\left[1-\hat{\eta} \varepsilon_{D}^{q} s_{L}-\hat{\varphi} \varepsilon_{D}^{y} s_{L}\right]-\left[(1-\hat{\eta})+\hat{\eta} \lambda \varepsilon_{D}^{q}+\hat{\varphi} \lambda \varepsilon_{D}^{y}\right] s_{K}} .
$$

The Cobb-Douglas production function implies that the real wage equals $(w / p)=$ $(1-\alpha) K^{\alpha} L^{-\alpha}$. Using Equation (A5), the real wage elasticity can then be written as:

$$
\frac{d \log (w / p)}{d \log L}=\alpha \frac{d \log K}{d \log L}-\alpha=\alpha \frac{\frac{d \log w}{d \log L}+1}{1+\lambda}-\alpha,
$$

The expression for the real wage elasticity is obtained by substituting (A18) into (A19). This step yields:

$$
\frac{d \log (w / p)}{d \log L}=\frac{-\lambda s_{K}+\hat{\eta} \lambda \varepsilon_{D}^{q} s_{K}+\hat{\varphi} \lambda \varepsilon_{D}^{y} s_{K}+\left[\hat{\eta}\left(\phi_{q}-1\right)+\hat{\varphi} \phi_{y}\right]}{(1+\lambda)\left[1-\hat{\eta} \varepsilon_{D}^{q} s_{L}-\hat{\varphi} \varepsilon_{D}^{y} s_{L}\right]-\left[(1-\hat{\eta})+\hat{\eta} \lambda \varepsilon_{D}^{q}+\hat{\varphi} \lambda \varepsilon_{D}^{y}\right] s_{K}} .
$$

Suppose that "generalized" product market neutrality holds. The bracketed term in the numerator of (A20) vanishes.

To show that the real wage elasticity must then be negative, recall that the rescaled elasticities $\hat{\eta}$ and $\hat{\varphi}$ defined in (A11) and (A12) are both greater than zero and less than 
one. It is straightforward to verify that the sum of these two elasticities is also less than one. The fact that $\hat{\eta}+\hat{\varphi}<1$ can be used to prove that the numerator of (A20) must be negative. In particular, the numerator equals $-\lambda s_{K}\left(1-\hat{\eta} \varepsilon_{D}^{q}-\hat{\varphi} \varepsilon_{D}^{y}\right)$. The maximum value that the income shares in this expression can attain is 1 . In that case, the numerator equals $-\lambda s_{K}[1-(\hat{\eta}+\hat{\varphi})]$. But the sum of the two elasticities $\hat{\eta}$ and $\hat{\varphi}$ must be less than one, hence the numerator is negative.

By using analogous arguments it is possible to show that the denominator of (A20) is positive. In particular, evaluate the denominator at $\lambda=0$. Using the properties of the rescaled elasticities noted above, it is easy to show that the denominator is positive at the lowest possible value of $\lambda$. By differentiating the denominator with respect to $\lambda$, it is also possible to show that the denominator is a monotonically increasing function of $\lambda$.

\section{Competing interests}

The IZA Journal of Migration is committed to the IZA Guiding Principles of Research Integrity. The author declares that he has observed these principles.

\section{Acknowledgments}

I am grateful to Edward Glaeser, Jeffrey Grogger, Daniel Hamermesh, Gordon Hanson, Lawrence Katz, Dani Rodrik, and an anonymous referee for comments on earlier drafts of this paper.

Responsible editor: Amelie F Constant

\section{Author details}

${ }^{1}$ Harvard University, Cambridge, MA 02138, USA. ${ }^{2}$ NBER, Cambridge, MA 02138, USA. ${ }^{3}$ IZA, Bonn, Germany.

Received: 28 August 2013 Accepted: 25 October 2013

Published: 12 November 2013

\section{References}

Benhabib J (1996) On the political economy of immigration. Eur Econ Rev 40(9):1737-1744

Borjas GJ (1995) The economic benefits from immigration. J Econ Perspect 9(2):3-22

Borjas GJ (2003) The labor demand curve Is downward sloping: reexamining the impact of immigration on the labor market. Q J Econ 118(4):1335-1374

Borjas GJ, Doran KB (2012) The collapse of the soviet union and the productivity of American mathematicians. Q J Econ 127(3):1143-1203

Borjas GJ, Freeman RB, Katz LF (1997) How much do immigration and trade affect labor market outcomes? Brook Pap Econ Act 1:1-67

Borjas GJ, Grogger J, Hanson GH (2008) Imperfect substitution between immigrants and natives: a reappraisal. NBER Working Paper, No. 13887, Cambridge MA

Borjas GJ, Grogger J, Hanson GH (2012) On estimating elasticities of substitution. J Eur Econ Assoc 10(1):198-210

Bowles S (1970) Aggregation of labor inputs in the economics of growth and planning: experiments with a two-level CES function. J Polit Econ 78(1):68-81

Card D (2001) Immigrant inflows, native outflows, and the local labor market impacts of higher immigration. J Labor Econ 19(1):22-64

Card D (2005) Is the new immigration really so bad? Economic Journal 115(4):F300-F323

Card D (2009) Immigration and inequality. Am Econ Rev 99(2):1-21

Card D, Lemieux T (2001) Can falling supply explain the rising return to college for younger men? a cohort-based analysis. Q J Econ 116(2):705-746

Cortes P (2008) The effect of low-skilled immigration on US prices: evidence from CPI data. J Polit Econ 116(3):381-422

Dixit A, Norman V (1980) The theory of international trade: a dual, general equilibrium approach. Cambridge University Press, New York, General Equilibrium Approach

Ewerhart C (2003) A short and intuitive proof of Marshall's rule. Economic Theory 22(2):415-418

Hamermesh D (1993) Labor demand. Princeton University Press, Princeton

Hicks JR (1932) The Theory of Wages. Macmillan, London

Hicks JR (1970) Elasticity of substitution again: substitutes and complements. Oxf Econ Pap 22(3):289-296

Kennan J (1998) The Hicks-Marshall rules of derived demand: an expository note. University of Wisconsin, Madison, Working Paper

Kennan J (2013) Open borders. Rev Econ Dyn 16:L1-L13

Lach S (2007) Immigration and prices. J Polit Econ 115(4):548-587

Manacorda M, Manning A, Wadsworth J (2012) The impact of immigration on the structure of wages: theory and evidence from Britain. J Eur Econ Assoc 10(1):120-151

Mishra P (2007) Emigration and wages in source countries: evidence from Mexico. J Dev Econ 82(1):180-199

Mundell RA (1957) International trade and factor mobility. Am Econ Rev 47(3):321-335

Olney W (2013) Remittances and the wage impact of immigration. Working Paper, Williams College 
Ottaviano GIP, Peri G (2005) Rethinking the gains from immigration: theory and evidence from the U.S. NBER Working Paper, p No. 11672, Cambridge MA

Ottaviano GIP, Peri G (2012) Rethinking the effect of immigration on wages. J Eur Econ Assoc 10(1):152-197 Rasmussen E (2013) How immigration can hurt a country. Indiana University, Working Paper

Saiz A (2007) Immigration and housing rents in American cities. J Urban Econ 61(2):345-371

Sato R, Tetsunori K (1973) On the elasticities of substitution and complementarity. Oxf Econ Pap 25(1):44-56

Wagner M (2009) Understanding the labor market impact of immigration. Working Paper, University of Chicago

Waldinger F (2010) Quality matters: the expulsion of professors and the consequences for PhD student outcomes in

Nazi Germany. J Polit Econ 118(4):787-831

doi:10.1186/2193-9039-2-22

Cite this article as: Borjas: The analytics of the wage effect of immigration. IZA Journal of Migration 2013 2:22.

Submit your manuscript to a SpringerOpen ${ }^{\circ}$ journal and benefit from:

$\checkmark$ Convenient online submission

- Rigorous peer review

- Immediate publication on acceptance

- Open access: articles freely available online

- High visibility within the field

- Retaining the copyright to your article

Submit your next manuscript at $\boldsymbol{\sim}$ springeropen.com 